\title{
Influence of the alkali metal cation on the fragmentation of monensin in ESI-MS/MS
}

\author{
Norberto Peporine Lopes ${ }^{1 *}$, Filipe Alexandre Almeida-Paz ${ }^{2}$, Paul Jonathan Gates ${ }^{3}$ \\ 1 Departamento de Física e Química, Faculdade de Ciências Farmacêuticas de Ribeirão Preto- Universidade de São \\ Paulo, ${ }^{2}$ Centro de Investigações em Materiais Cerâmicos e Compósitos- Departamento de Química- Universidade de \\ Aveiro- CICECO, ${ }^{3}$ School of Chemistry, University of Bristol- Bristol-United Kingdom
}

*Correspondence:

N. P. Lopes

Faculdade de Ciências Farmacêuticas de Ribeirão Preto - Universidade de

São Paulo

Via do Café $\mathrm{S} / \mathrm{N}$

14040-903 - Ribeirão Preto - SP, Brasil

E-mail: npelopes@fcfrp.usp.br
The MS/MS fragmentation of the alkali metal complexes of monensin A are studied. The increase in alkali metal ionic radii decreases the ability of the Grob-Wharton fragmentation mechanism to occur and reduces the overall degree of fragmentation. Conversely, the electronegativity of the metal cation is related to the number of fragment ions observed.
Uniterms

- Polyether ionophore

- Monensin

- Alkali metal complex

- Electrospray tandem mass spectrometry

\section{INTRODUCTION}

Polyether ionophore antibiotics exhibit a high degree of commercial importance as anti-coccidiosis agents (coccidiostats) and are used as everyday feed supplements in farming, especially of poultry and cattle. Coccidiosis has a serious economic impact through increasing animal mortality and reducing growth rates (Elliott et al., 1998). Polyether ionophores are naturally occurring compounds that usually contain a carboxylic acid along with several cyclic ether oxygen atoms (from two to five) as well as hydroxy and carbonyl groups. It is believed that their biological activity is based upon their ability to form strongly bound electrically neutral complexes with alkali metal cations (Martinek et al., 2000) (especially with $\mathrm{Na}^{+}$ and $\mathrm{K}^{+}$) and thus disrupt the transportation of these ions across the cell membrane barrier (Riddell, 1992) This ability has the result of making them toxic in high dose rates and has lead to worries about their presence in the human food chain. These factors have created significant levels of interest in the polyethers, both in the fields of drug development and metabolite identification.
Monensin A and B (Figure 1) can adopt a quasi-cyclic conformation forming strongly bound adducts with sodium cations (Martinek et al., 2000). Previously published crystallographic data for monensin A (Paz et al., 2003) and B (Barrans et al., 1982; Walba et al., 1986) sodium salts show the metal cation in a distorted octahedral environment, being chelated by six oxygen atoms $(5,6,7$, 8,9 , and 10 - see Figure 1). The analysis of the structure of monensin in solution was recently carried out using NOESY distance restraints and molecular modelling, with the reported results being in good agreement with the crystal structures (Martinek et al., 2000). An inspection of the Cambridge Structural Database (CSD) reveals that an increase in the ionic radii of the metal ion leads to a larger $M^{+} \ldots \mathrm{O}$ average distance (Figure 2, Table I). This idea was used to calculate values for the rubidium ion (Martinek et al., 2000) following the experimental trend for $\mathrm{Li}^{+}, \mathrm{Na}^{+}$and $\mathrm{K}^{+}$. Consequently, it is feasible to deduce that $\mathrm{Cs}^{+}$ions will have an even larger coordination distance within the monensin complex.

Monensin $\mathrm{A}\left(\mathrm{C}_{36} \mathrm{H}_{60} \mathrm{O}_{10}, 670 \mathrm{Da}\right)$ is the most investigated polyether by low-resolution mass 


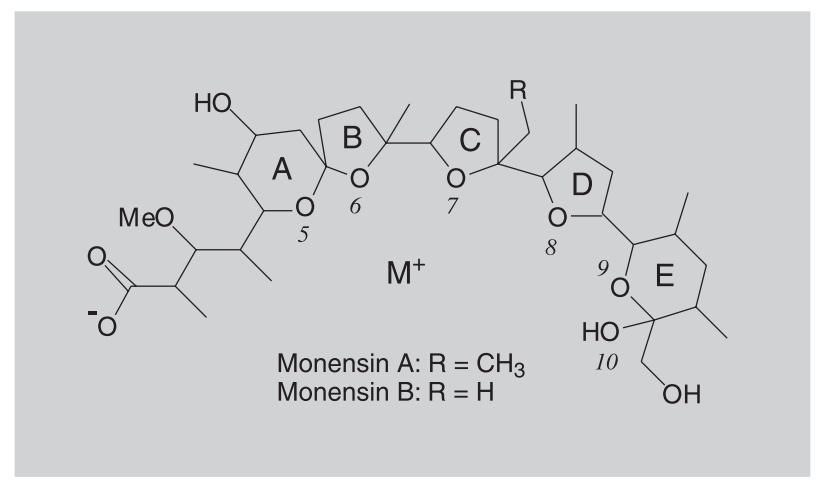

FIGURE 1 - The structure of the monensin salts.

spectrometry (Schen, Brodbelt, 2000; Kiehl et al., 1998; Kim et al., 1996; Volmer, Lock, 1998; Lopes et al., 2001, $2002 \mathrm{a}, 2002 \mathrm{~b}$ ). The high affinity for $\mathrm{Na}^{+}$and $\mathrm{K}^{+}$ions usually limits these studies to the sodiated complex. It was found that added crown-ethers to the solution competed for the sodium ions and the monensin protonated molecule was observed (Lopes et al., 2001). The fragmentation studies performed within this group (Lopes et al., 2001; Lopes et al., 2002a) show that the ion of $m / z 671$ can consist of two isomeric ions with the same accurate-mass: either the monensin protonated molecule or a ion with a different structure derived from the loss of water from the hydrated adduct of monensin. The MS/ MS of the hydrated adduct ion of $m / z 689$ shows a simple pattern of fragmentation based almost entirely on simple neutral losses. Whereas previous publish data reported that the protonated monensin A of $m / z 671$ fragments via a Grob-Wharton type mechanism, initiated by the protonation of the hydroxy group in ring A followed by loss of water (Lopes et al., 2002a), the fragmentation of the protonated molecule generally involves opening of ring $\mathrm{A}$. The complete fragmentation mechanism for the monensin sodium salt by accurate mass spectrometry was recently proposed (Lopes et al., 2002b). The ESIMS/MS analysis of the sodiated molecule showed that the common fragmentations are of the Grob-Wharton type induced by the sodium cation. Two different routes were observed which form the fragment ions of $\mathrm{m} / \mathrm{z} 479$ $\left(\mathrm{C}_{25} \mathrm{H}_{44} \mathrm{O}_{7} \mathrm{Na}^{+}\right)$and $m / z 501\left(\mathrm{C}_{28} \mathrm{H}_{46} \mathrm{O}_{6} \mathrm{Na}^{+}\right)$. These key ions produce most of the secondary ions observed by either pericyclic rearrangements or simple neutral losses (Lopes et al., 2002b). Monensin can coordinate to several diferents alkali metals cations, but until now there are no data about the influence of the cation's eletronegativity and ionic radii on the fragmentation chemistry. The aim of this work is therefore to verify the influence of alkali metal cations in the fragmentation of monensin.

\section{EXPERIMENTAL}

\section{Material}

All chemicals are available commercially and were used as received without further purification. Monensin A was obtained as a sodium salt from Sigma (Poole, Dorset). The alkali metal chlorides and acetonitrile (HPLC grade) were obtained from Aldrich (Gillingham, Dorset). Deionised water was used throughout the study. Stock solutions of monensin $\left(10 \mathrm{mg} \mathrm{ml}^{-1}\right)$ were prepared in acetonitrile and stored at $4{ }^{\circ} \mathrm{C}$. Dilute solutions of monensin were prepared daily in $80 \% \mathrm{v} / \mathrm{v}$ (acetonitrile/ water) with $0.25 \mathrm{mg} \mathrm{ml}^{-1}$ as the final concentration. An excess (4 equiv) of the appropriate alkali metal chloride was added to the monensin solution before analysis.

\section{Instrumentation}

Mass spectral analyses were performed on a BioApex II (4.7 Tesla) Fourier-transform ion cyclotron resonance instrument (Bruker Daltonics, Billerica, USA). Solutions were infused by syringe pump through the Apollo ESI source at $100 \mu \mathrm{L} / \mathrm{h}$. Fragmentation analyses were performed on the isolated parent ions by sustained off-resonance irradiation collision induced dissociation (SORI-CID) using $\mathrm{CO}_{2}$ collision gas. Precursor ions were selectively isolated through correlated sweep isolation with a short period of collisional cooling after isolation. In some cases, was required to isolate the precursor ion. The cell conditions were tuned to fragment enough of the precursor ion to observe a spectrum of good intensity across the required mass range. Sequential fragmentation steps were usually performed on optimized precursor ions from the previous step. The ESI spectra and isolation experiments were performed at a resolution of approximately 50,000 and the $\mathrm{MS}^{\mathrm{n}}$ spectra had a resolution of approximately 80,000 . Usually 8 or 16 individual scans were combined to produce a spectrum. On some occasions (when the signal was very weak) as many as 40 scan summations were required to produce spectra with a good signal:noise ratio. An accuratemass calibration was obtained for all sequential mass spectrometry data through a post acquisition application of a calibration created from the MS/MS of a known standard achieved under the same CID and cell conditions. Mass-accuracies were well within $1 \mathrm{ppm}$ of the theoretical masses for most ions observed. The diagrams of the alkali metal complexes were created using Crystal Diamond. 


\section{RESULTS AND DISCUSSION}

The accurate-mass MS/MS analysis confirms that all the monensin fragments observed in the spectra of the alkali metal adducts are produced through either a Grob-Wharton type mechanism or by simple neutral losses (Figure 2 shows the lithium complex spectrum). The only exception is the $\mathrm{Rb}$ and $\mathrm{Cs}$, that leave the monensin and only $\mathrm{Rb}^{+}$and $\mathrm{Cs}^{+}$are observed. There are, however, significant differences in the spectra of the other metal complexes. The spectrum of the lithium complex shows fragmentation at threshold collision energies, but only a few fragments ions are observed. The protonated monensin also fragment at threshold collision energies and also shows few fragments, but protonated monensin fragmentation start by a charge remote mechanism

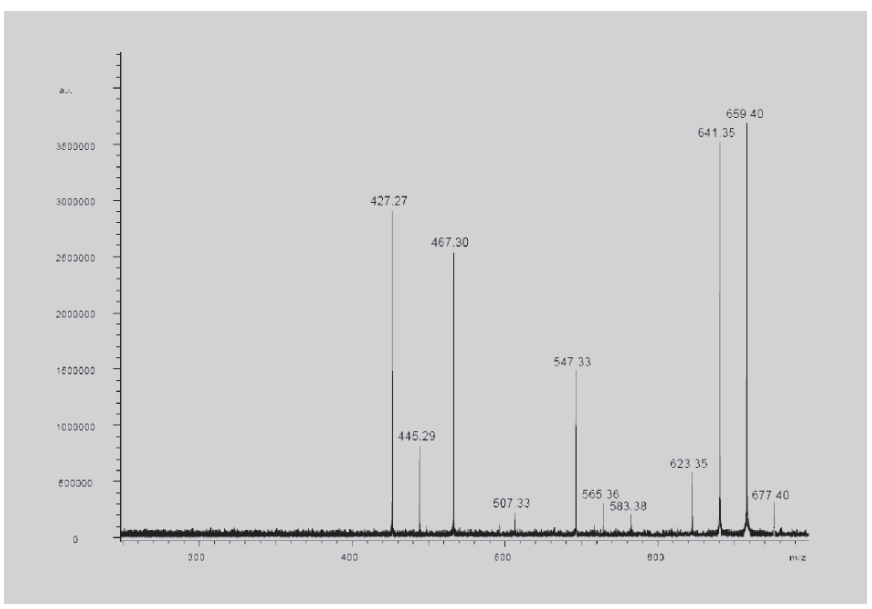

FIGURE 2 - MS ${ }^{\mathrm{n}}$ spectra of Monensin-Lithium product.
(Lopes et al., 2002b) and in this case the lithium is still in the fragments. In addition, only very few neutral losses were observed from the parent ion with none occurring from the Grob-Wharton products. On the other hand, the spectrum of the sodium complex only shows water losses from the parent ion at threshold collision energies. Much higher energies (or $\mathrm{MS}^{3}$ ) were required to induce the Grob-Wharton mechanism. A large number of neutral losses were then observed. The spectrum of the potassium complex only shows neutral losses from the ion. Higher collision energies (or $\mathrm{MS}^{3}$ ) did not induce any further fragmentation. The spectra of the rubidium and caesium complexes showed no fragmentation at all, apart from the peaks for the alkali metal cation. The MS/MS data for all the alkali metal complexes are summarised in Figure 4.

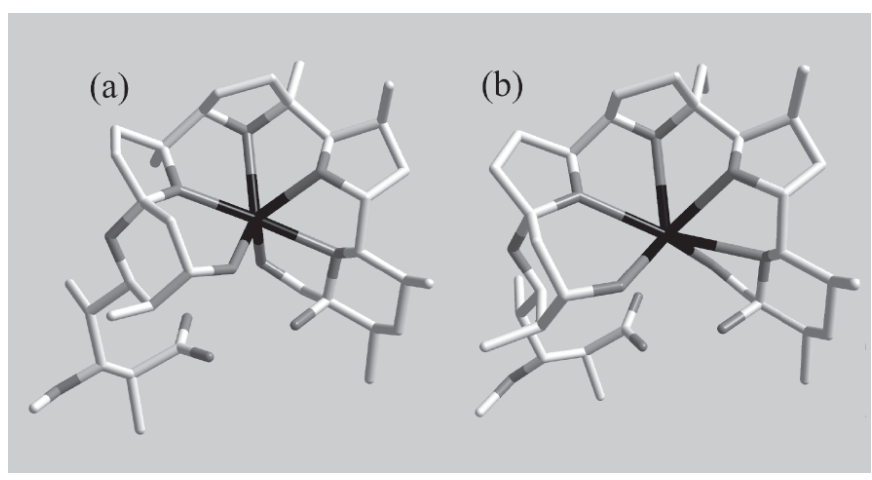

FIGURE 3 - The crystallographic structures of monensin with the alkali metals. Structure (a) sodium / monensin B complex. Structure (b) potassium / monensin A complex. (See data in Table I).

TABLE I - Metal-to-oxygen distances (in $\AA$ ) for the crystals of the monensin alkali metal complexes, along with the values of ionic radii and electronegativity of the respective metals

\begin{tabular}{lccccc}
\hline Cation, $M^{+}$ & $\mathbf{L i}^{+(\mathrm{a})}$ & $\mathbf{N a}^{+(\mathrm{b})}$ & $\mathbf{K}^{+(\mathrm{c})}$ & $\mathbf{R b}^{+(\mathrm{d})}$ & $\mathbf{C s}^{+}$ \\
\hline Ionic radii(pm) ${ }^{(\mathrm{e})}$ & 90 & 116 & 152 & 166 & 181 \\
\hline$\chi_{\mathrm{P}}{ }^{(\mathrm{f})}$ & 0.98 & 0.93 & 0.82 & 0.82 & 0.79 \\
\hline$M^{+} \ldots \mathrm{O}(5)$ & $2.037(8)$ & $2.331(0)$ & $2.650(2)$ & 2.99 & - \\
$M^{+} \ldots \mathrm{O}(6)$ & $2.159(8)$ & $2.350(0)$ & $2.659(2)$ & 2.95 & - \\
$M^{+} \ldots \mathrm{O}(7)$ & $2.326(8)$ & $2.471(0)$ & $2.785(2)$ & 2.91 & - \\
$M^{+} \ldots \mathrm{O}(8)$ & $2.381(8)$ & $2.434(0)$ & $2.717(2)$ & 3.11 & - \\
$M^{+} \ldots \mathrm{O}(9)$ & $2.381(8)$ & $2.461(0)$ & $2.796(2)$ & 3.17 & - \\
$M^{+} \ldots \mathrm{O}(10)$ & $2.098(8)$ & $2.357(0)$ & $2.785(2)$ & 3.34 & - \\
Average $M^{+} \ldots \mathrm{O}$ & 2.23 & 2.40 & 2.73 & 3.08 & $3.2^{(\mathrm{g})}$ \\
\hline
\end{tabular}

(a) CSD ref. DOPVEJ (Monensin B-lithium monohydrate) (Walba et al., 1986). ${ }^{\text {(b) }}$ CSD ref. BELDAX (Monensin Bsodium monohydrate) (Barrans et al., 1982). ${ }^{(c)}$ CSD ref. FECROU10 (Monensin A-potassium dihydrate) (Pangborn et al., 1987). ${ }^{(\mathrm{d})}$ From the theoretical calculations made by Martinek et al., 2000. ${ }^{(\mathrm{e})}$ Effective ionic radii of the elements for a coordination number 6 (Shennon, 1976)..$^{(\mathrm{f})}$ Electronegativity according to Pauling (Allred, 1961). ${ }^{(\mathrm{g})}$ Value calculated considering a linear increase in the $\mathrm{M}^{+} \ldots \mathrm{O}$ distance with the ionic radii. 
An increase in the ionic radius leads to the corresponding decrease in electronegativity of the metal and, consequently, to an increase in the metal-ligand average distance (Table 1). The small ionic radius and high electronegativity of lithium makes it the strongest Lewis acid in the series. This high acidity produces the observed increase in the total degree of fragmentation of monensin. This is probably caused by the attraction of the electrons from the oxygen (O4 or O5 - by two different pathways) by the lithium cation. It is also observed that the energy required to fragment the lithium complex is lower than that required to fragment the sodium and potassium complexes. Conversely, lithium forms tight complexes with the initial fragment ions thus preventing further neutral losses.

The MS/MS analysis of the sodium complex showed different behaviour to that observed for the lithium complex. The coordination environment for sodium has a higher average distance that permits the attraction of the electrons to start the Grob-Wharton fragmentation, but the lower electronegativity of sodium results in a lower degree of fragmentation. Fragmentation of the sodium complex, however, produced significantly more fragment ions through neutral elimination (Figure 4). The energy required to initiate the Grob-Wharton mechanism was much higher than for the lithium complex. In fact, it was easier to produce the Grob-Wharton fragment ions in the $\mathrm{MS}^{3}$ analysis of the water loss peak.

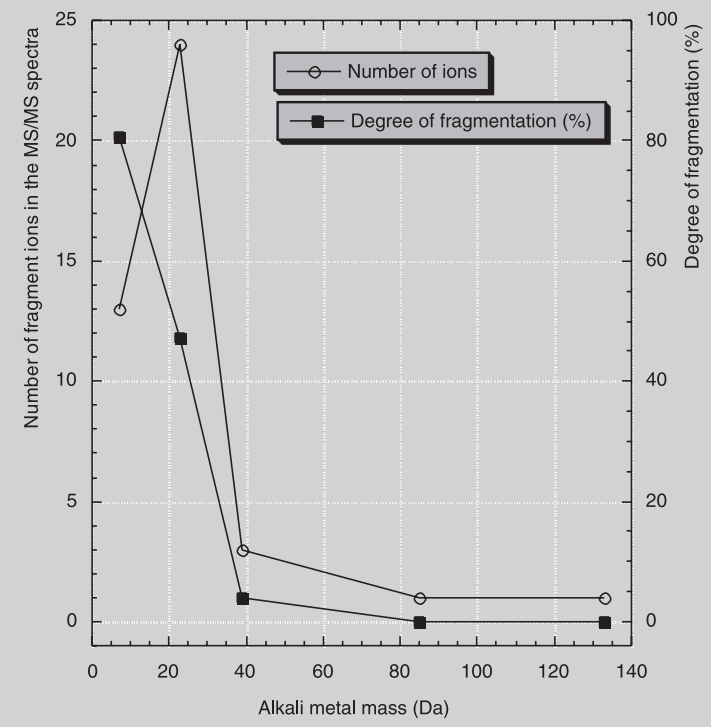

FIGURE 4 - Graph of degree of fragmentation (sum of the intensities of the fragment ions relative to the intensity of the unfragmented parent ion) and number of fragment ions observed in the tandem mass spectra with the alkali metal mass (Da).
Figure 3 shows how the theoretical simulation of the metal ionic radius determines the arrangement of the quasi-cyclic conformation of the complexes. The model exhibits a good correlation with the crystallography data deposited at Cambridge University Data Center. The increase in the average coordination distance in the monensin potassium complex compared to lithium and sodium complexes (Table 1) reduces both the number and the degree of fragmentation and no Grob-Wharton process occurs. Only the simple neutral losses from the parent ion were observed (Figure 4). Increasing the collision energy resulted in an increase in the intensity of the neutral loss ions. $\mathrm{MS}^{3}$ analysis showed the same neutral losses.

In the fragmentation of the rubidium and caesium complexes, only the metal ions $\left(\mathrm{Rb}^{+}\right.$and $\left.\mathrm{Cs}^{+}\right)$were formed as fragments. Increasing the collision energy just resulted in a more intense signal for the cation. It was not possible to induce any monensin fragment ions. This difficulty is presumably due to a significant increase in the ionic radius and reduction in electronegativity (Table 1), which leads to a weakening of the metal-to-ligand interaction. Consequently, the bound metal cation can be lost even at threshold collision energies.

\section{CONCLUSIONS}

The results of this study indicate that the metal ionic radius and electronegativity are related to the intensity and number of fragment ions produced by the Grob-Wharton mechanism for monensin alkali metal complexes in ESIMS/MS. The high affinity of monensin for sodium cations explains why only a single water loss is observed in the $\mathrm{MS} / \mathrm{MS}$ of the protonated sodium complex and much higher energies than normal (or $\mathrm{MS}^{3}$ ) are required to induce full fragmentation whereas full fragmentation of the lithium complex occurs at threshold collision energies. These findings demonstrate that differences in Lewis acidity between the alkali metals influence their ability to induce the Grob-Wharton fragmentation.

\section{ACKNOWLEDGEMENTS}

This work was carried out at University of Cambridge, Department of Chemistry under the supervision of Professor James Staunton. Funding was provide by "Fundação de Amparo à Pesquisa do Estado de São Paulo" (Brazil), "Fundação Para a Ciência e Tecnologia" (Portugal), Unilever Safety and Environmental Assurance Centre (Bedford, U.K.) 


\section{RESUMO}

\section{Influência de cátions de metais alcalinos sobre a fragmentação de monensina em ESI-MS/MS}

O presente trabalho relata os estudos de fragmentação por espectrometria de massas seqüencial de complexos formados pela monensina A e uma série de metais alcalinos. Foi observado que o aumento do raio ionnico do metal alcalino levou a uma diminuição do mecanismo de fragmentação do tipo Grob-Wharton e ao grau de fragmentação. Por outro lado, a maior eletronegatividade mostrou estar relacionada ao número de fragmentos observados.

UNITERMOS: Poliéteres. Monensina. Complexos de metais alcalinos. Electrospray. Espectrometria de massas.

\section{REFERENCES}

ALLRED,A. L. Electronegativity values from thermochemical data. J. Inorg. Nucl. Chem., v. 17, p. 215-221, 1961.

BARRANS Y.; ALLEAUME M.; JEMINET G. Sodium complex of the monohydrated ionophore monensin-b. Acta Crystallogr., Sect. B., v. 38, p. 1144-1149, 1982.

WALBA, D. M.; HERMSMEIER, M.; HALTIWANGER, R. C.; NOORDIK, J. H. Crystal structures of monensin B lithium and silver salts. J. Org. Chem., v. 51, p. 245247, 1986.

ELLIOTT, C. T.; KENNEDY, D. G.; MCCAUGHEY, W. J. Methods for the detection of polyether ionophore resides in poultry. Analyst, v. 123, p. 45-56, 1998.

KIEHL, D. E.; JULIAN, R. K.; KENNINGTON, A. S. Electrospray ionization mass spectrometry with insource collision-induced dissociation of monensin factors and related metabolites. Rapid Commun. Mass Spectrom., v. 12, p. 903-910,1998.

KIM, Y. H.; YOO, J. S.; LEE, C. H.; GOO, Y. M.; KIM, M. S. Application of Fast Atom Bombardment Combined with Tandem Mass Spectrometry to the Structural Elucidation of O-demethylabierixin and Related Polyether Antibiotics. J. Mass Spectrom., v. 31, p. 855860, 1996.

LOPES, N. P.; STARK, C. B. W.; HONG, H.; GATES, P. J.; STAUNTON, J. A study of the effect of $\mathrm{pH}$, solvent system, cone potential and the addition of crown ethers on the formation of the monensin protonated parent ion in electrospray mass spectrometry. Analyst, v. 126, p. 1630-1632, 2001.

LOPES, N. P.; STARK, C. B. W.; GATES, P. J.; Staunton, J. Fragmentation studies on monensin A by sequential electrospray mass spectrometry. Analyst, v. 127, p.503506, 2002.

LOPES, N. P.; STARK, C. B. W.; GATES, P. J.; STAUNTON, J. Fragmentation studies on monensin A and B by accuratemass electrospray tandem mass spectrometry. Rapid Commun. Mass Spectrom., v. 16, p. 414-420, 2002.

MARTINEK, T.; RIDDELL, F. G.; WILSON, C.; WELLER, C. T. The conformations of monensin-A metal complexes in solution determined by NMR spectroscopy. J. Chem. Soc., Perkin Trans., v. 2, p. 35-41, 2000.

PANGBORN, W.; DUAX, W.; LANGS, D. The hydrated potassium complex of the ionophore monensin-a. J. Am. Chem. Soc. v. 109, p. 2163-2165, 1987.

PAZ, F. A. A.; GATES, P. J.; FOWLER, S.G. A.; HARVEY, B.; LOPES, N. P.; STARK C. B. W.; STAUNTON, J.; KLINOWSKI J.; SPENCER, J.B. Sodium monensin dehydrate. Acta Crystallographica., Sect.E., v. 59, p. 1050-1052, Parte 11, 2003.

RIDDELL F.G. Ionophoric antibiotics. Chem. Brit., v. 28, p. 533-\&, 1992.

SHANNON, R.D. Revised effective ionic-radii and systematic studies of interatomic distances in halides and chalcogenides. Acta Cryst. A32, p.751-767, 1976.

SHEN, J.; BRODBELT, J.S. Characterization of ionophoremetal complexes by infrared multiphoton photodissociation and collision-activated dissociation in a quadrupole ion trap mass spectrometer. Analyst., v. 125, p.641-650, 2000.

VOLMER, D.A.; LOCK, C.M. Electrospray ionization and collision-induced dissociation of antibiotic polyether ionophores. Rapid Commun. Mass Spectrom. v. 12, p.157-164, 1998.

WALBA, D.M.; HERMSMEIER, M.; HALTIWANGER, R. C.; NOORDICK, J.swH. Crystal structures of monensin B lithium and silver salts. J. Org. Chem. v. 51, p. 245-247, 1986.

Recebido para publicação em 04 de abril de 2005. Aceito para publicação em 17 de abril de 2006. 